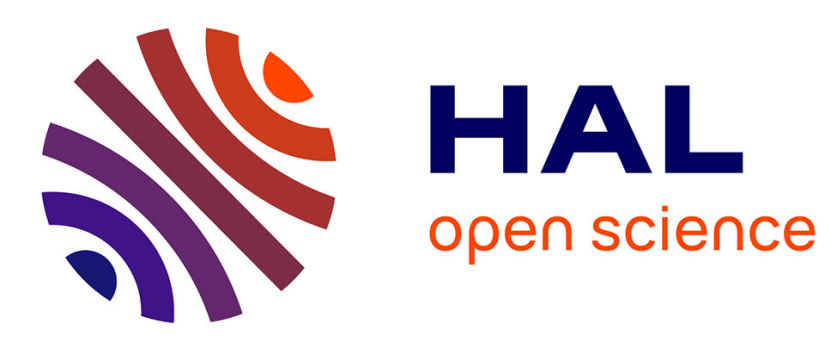

\title{
Discovery of new inhibitors of aldo-keto reductase 1C1 by structure-based virtual screening
}

\author{
Petra Brožič, Samo Turk, Tea Lanišnik Rižner, Stanislav Gobec
}

\section{To cite this version:}

Petra Brožič, Samo Turk, Tea Lanišnik Rižner, Stanislav Gobec. Discovery of new inhibitors of aldoketo reductase 1C1 by structure-based virtual screening. Molecular and Cellular Endocrinology, 2009, 301 (1-2), pp.245. 10.1016/j.mce.2008.08.002 . hal-00532060

\section{HAL Id: hal-00532060 https://hal.science/hal-00532060}

Submitted on 4 Nov 2010

HAL is a multi-disciplinary open access archive for the deposit and dissemination of scientific research documents, whether they are published or not. The documents may come from teaching and research institutions in France or abroad, or from public or private research centers.
L'archive ouverte pluridisciplinaire HAL, est destinée au dépôt et à la diffusion de documents scientifiques de niveau recherche, publiés ou non, émanant des établissements d'enseignement et de recherche français ou étrangers, des laboratoires publics ou privés. 


\section{Accepted Manuscript}

Title: Discovery of new inhibitors of aldo-keto reductase $1 \mathrm{C} 1$ by structure-based virtual screening

Authors: Petra Brožič, Samo Turk, Tea Lanišnik Rižner, Stanislav Gobec

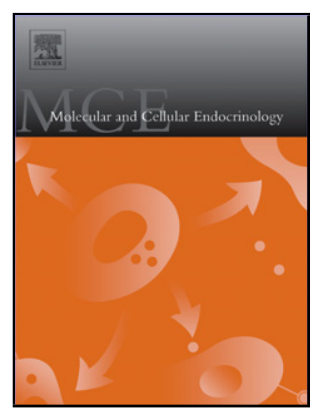

PII:

S0303-7207(08)00339-0

DOI: doi:10.1016/j.mce.2008.08.002

Reference: MCE 6937

To appear in: Molecular and Cellular Endocrinology

Received date: $1-7-2008$

Revised date: $2-8-2008$

Accepted date: $3-8-2008$

Please cite this article as: Brožič, P., Turk, S., Rižner, T.L., Gobec, S., Discovery of new inhibitors of aldo-keto reductase $1 \mathrm{C} 1$ by structure-based virtual screening, Molecular and Cellular Endocrinology (2007), doi:10.1016/j.mce.2008.08.002

This is a PDF file of an unedited manuscript that has been accepted for publication. As a service to our customers we are providing this early version of the manuscript. The manuscript will undergo copyediting, typesetting, and review of the resulting proof before it is published in its final form. Please note that during the production process errors may be discovered which could affect the content, and all legal disclaimers that apply to the journal pertain. 


\section{Discovery of new inhibitors of aldo-keto reductase 1C1 by structure-based virtual screening}

Petra Brožič ${ }^{1}$, Samo Turk ${ }^{2}$, Tea Lanišnik Rižner ${ }^{1}$, Stanislav Gobec ${ }^{2}$ *

${ }^{1}$ Institute of Biochemistry, Faculty of Medicine, University of Ljubljana, 1000 Ljubljana, Slovenia

${ }^{2}$ Faculty of Pharmacy, University of Ljubljana, 1000 Ljubljana, Slovenia

*Corresponding Author:

Dr. Stanislav Gobec

Faculty of Pharmacy

University of Ljubljana

Aškerčeva 7

1000 Ljubljana

Slovenia

Tel: $+386-1-4769585$

Fax: +386-1-4258031

Email: gobecs@,ffa.uni-1j.si 


\begin{abstract}
Aldo-keto reductase $1 \mathrm{C} 1$ is a hydroxysteroid dehydrogenase that inactivates progesterone by converting it to $20 \alpha$-hydroxyprogesterone. It also inactivates $3 \alpha, 5 \alpha$-tetrahydroprogesterone, an allosteric modulator of the $\gamma$-aminobutyric acid receptor that has anaesthetic, analgesic, anxiolytic and anticonvulsant effects. Inhibitors of aldo-keto reductase $1 \mathrm{C} 1$ are thus very interesting as potential agents for the treatment of endometrial cancer, premenstrual syndrome, catamenial epilepsy, and depressive disorders, and for the maintenance of pregnancy. We have used the molecular docking program eHiTS for virtual screening of 1,990 compounds from the National Cancer Institute "Diversity Set". Fifty compounds with the highest predicted binding energies were then evaluated in vitro. Three structurally diverse hits were obtained that inhibit aldo-keto reductase $1 \mathrm{C} 1$ in the low micromolar range of $\mathrm{IC}_{50}$ values. These hits represent promising starting points for structural optimization in hit-to-lead development.
\end{abstract}

Keywords: AKR1C1 inhibitors; virtual high-throughput screening; NCI Diversity Set; eHiTS. 


\section{Introduction}

Hydroxysteroid dehydrogenases (HSDs) are involved in the synthesis and inactivation of all classes of steroid hormones. HSDs belong to two protein superfamilies: the short-chain dehydrogenase/ reductase (SDR) superfamily (Persson et al., 1991; Jornvall et al., 1995) and the aldo-keto reductase (AKR) superfamily (Penning, 2003). Human AKR HSDs belong to the AKR1C subfamily and regulate the concentrations of active and inactive androgens, estrogens and progestins in target tissues, and thus regulate ligand occupancy and transactivation of the nuclear steroid hormone receptors (Dufort et al., 1999; Dufort et al., 2001; Penning et al., 2000).

AKR1C1 acts preferentially as a $20 \alpha-\mathrm{HSD}$ and inactivates progesterone by converting

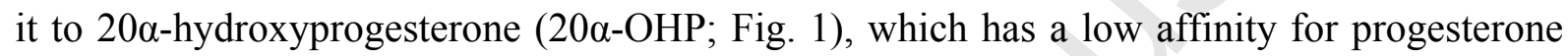
receptors (Penning et al., 2000). AKR1C1 is also active towards $3 \alpha, 5 \alpha-$

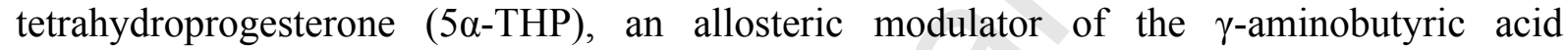
$(\mathrm{GABA})_{\mathrm{A}}$ receptor, and it thereby exhibits anaesthetic, analgesic, anxiolytic and anticonvulsant effects. Here, $5 \alpha$-THP is converted into the inactive $5 \alpha$-pregnane-3 $3,20 \alpha$-diol (Penning et al., 2000; Griffin et al., 1999; Nobel et al. 2001). Inhibitors of AKR1C1 are thus very interesting as potential agents for the treatment of endometrial cancer, premenstrual syndrome, catamenial epilepsy, and depressive disorders, and for the maintenance of pregnancy (Lanišnik Rižner et al., 2006; Higaki et al., 2003).

Although AKR1C1 represents an emerging therapeutic target, only a few inhibitors of AKR1C1 have been reported to date. Dietary phytoestrogens ( et al., 2006), benzodiazepines (Usami et al., 2002), benzofuranes and phenolphthalein derivatives (Higaki et al., 2003) have been shown to inhibit AKR1C1 at low micromolar concentrations. Indomethacin, flufenamic acid, $N$-phenylanthranilic acid derivatives, salicylates and some related non-steroidal antiinflammatory agents are also very potent inhibitors (Bauman et al., 2005; Dhagat et al., 2007). The availability of the X-ray crystal structure of AKR1C1 as a complex with $20 \alpha-\mathrm{OHP}$ (Couture et al., 2003) enabled us to perform a virtual high-throughput screening with the National Cancer Institute (NCI) "Diversity Set" bank of compounds, and to biochemically evaluate the most promising inhibitors that were selected by the eHiTS software. Three inhibitors were obtained that represent promising starting points for further optimization. 


\section{Materials and methods}

\section{Virtual high-throughput screening}

The Diversity Set that consists of 1,990 compounds in DMSO solution in 96-well microtiter plates was obtained from the NCI. Compounds detected as hits after an initial screening were acquired from the NCI as solid samples. The three-dimensional (3D) structures of compounds from the NCI Diversity Set were obtained from the NCI web page (http://dtp.nci.nih.gov/dw/testmasters/chem3d.html). No special preparation of the 3D structures was carried out since eHiTS automatically evaluates all of the possible protonation states for ligands and enzymes. Virtual screening was carried out on a workstation with two Xeon $2.4 \mathrm{GHz}$ processors, 2 GB RAM, $120 \mathrm{~GB}$ hard drive and Nvidia Geforce $6600 \mathrm{GT}$ graphic card running Red Hat Linux 9.0. eHiTS 6.0 from SimBioSys Inc. was used for active site detection and docking (Zsoldos et al., 2006a). Open Babel was used for manipulating the various chemical formats of ligands. PyMol from DeLano Scientific was used for visual inspection of results and graphical presentations. CACTVS tools were used for $2 \mathrm{D}$ structure visualization.

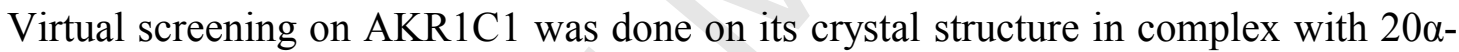
OHP (PDB entry 1MRQ). This structure was solved at $1.59 \AA$ resolution (Couture et al., 2003) and was used without any modifications. The enzyme was initially prepared with eHiTS. Active-site detection was carried out using the "-complex" parameter with high accuracy. The program automatically detected the ligand in the complex and selected the part of enzyme within a $7 \AA$ margin around the ligand to be the active site. The NCI Diversity Set was then docked to the active site using the fastest mode of docking (accuracy set to 1). Two hundred of the best scoring compounds from the first run were then re-docked with a higher accuracy setting (set to 6) and scored with eHiTS_Score, which is included in the eHiTS software package (Zsoldos et al., 2006b).

\section{Expression and purification of recombinant AKR1C1}

pGEX-AKR1C1 (constructed from a pcDNA3-AKR1C1 vector provided by Dr. Trevor M. Penning) (Brožič et al., 2006) was transferred into the BL21 Escherichia coli strain. The cells were then grown in Luria-Bertani medium containing $100 \mu \mathrm{g} / \mathrm{ml}$ ampicillin, at $37{ }^{\circ} \mathrm{C}$ in a rotary shaker, until an $\mathrm{OD}_{600}$ of 1.0 had been reached. Expression of $\mathrm{AKR} 1 \mathrm{C} 1$ was induced by IPTG at a final concentration of $1 \mathrm{mM}$, and the incubation was continued for $16 \mathrm{~h}$ at $24{ }^{\circ} \mathrm{C}$ (Krazeisen et al., 2001; Couture et al., 2002). The preparation of cell extracts, the purification 
of glutathione-S-transferase (GST)-fusion proteins by affinity binding to glutathioneSepharose, and the cleavage with thrombin, were all performed as described in the GST Gene Fusion System Handbook (Amersham Biosciences). Protein concentrations were determined using the Bradford method, with bovine serum albumin as standard, and the homogeneity of the protein was checked by SDS PAGE followed by Coomassie Blue staining.

\section{Inhibition assay}

Human recombinant AKR1C1 catalyzes the oxidation of 1-acenaphthenol in the presence of the coenzyme $\mathrm{NAD}^{+}$. The reaction was followed spectrophotometrically by measuring the increase in NADH absorbance $\left(\varepsilon_{\lambda 340}=6220 \mathrm{M}^{-1} . \mathrm{cm}^{-1}\right)$ in the absence and presence of each of the compounds. The screening was carried out in a $0.3-\mathrm{ml}$ volume that included $100 \mathrm{mM}$ phosphate buffer ( $\mathrm{pH}$ 6.5), 0.005\% Triton X-114 and 5\% DMSO as a co-solvent. A substrate concentration close to the determined $\mathrm{Km}$ value was used, with $2.3 \mathrm{mM}$ coenzyme and 1.0 $\mu \mathrm{M}$ enzyme. The concentrations of the compounds ranged from $1 \mu \mathrm{M}$ to $100 \mu \mathrm{M}$. The measurements were performed on a Tecan Safire ${ }^{2 \mathrm{TM}}$ microplate reader, with initial velocities calculated, and the $\mathrm{IC}_{50}$ values were determined graphically from plots of $\log _{10}$ (inhibitor concentration) versus \% inhibition, using GraphPad Prism Version 4.00 (GraphPad Software, Inc.). 


\section{Results and Discussion}

Virtual screening is an automated computational technique that can be used for screening large databases of compounds and that is gaining importance in modern drug discovery. Its aim is to reduce large numbers of compounds to smaller subsets that are more likely to contain biologically active compounds. Virtual screening applied to the discovery of new enzyme inhibitors involves docking, the computational fitting of structures of compounds to the active site of an enzyme, and scoring and ranking each compound. The highest ranked compounds are then tested for their activities in a biological or biochemical assay (Guido et al., 2008).

For our docking experiments, we used eHiTS 6.0 software. eHiTS is a program for flexible ligand docking that applies systematic algorithms to sample all of the possible degrees of freedom of a molecule. Ligands were first divided into rigid fragments and flexible chains, and each fragment was then docked independently into the active site. The program applied the fast graph matching algorithm to reconstruct the original molecule from the docking of its small rigid fragments. They were then reconnected with flexible chains, and local energy optimization within the receptor was then performed, followed by scoring. The scoring was based on the eHiTS_Scores of a statistically derived empirical scoring function (Zsoldos et al., 2006a; Zsoldos et al., 2006b).

The NCI "Diversity Set" is a library of 1,990 compounds that were selected from the original NCI-3D structural database for their unique scaffolds. The compounds are freely available as solutions in DMSO in microtiter plates. Each compound from the NCI Diversity Set was docked to AKR1C1 using eHiTS, and this resulted in a list of potential inhibitors ranked according to the eHiTS scoring function. Only the top 50 compounds (Table 1) were then evaluated in in-vitro biochemical assays. Among the compounds tested, three structurally diverse hits (Table 2) were obtained that inhibited the enzyme in the low micromolar range of $\mathrm{IC}_{50}$ values. As these inhibitors have new scaffolds they can be used as promising starting points for further synthetic structural modifications and optimization as well as for additional computer-assisted methods like 2D and 3D similarity searches.

The docking poses predicted by eHiTS for the two best inhibitors are presented in Figures 2 and 3. The position of inhibitor NSC292213 overlaps with the co-crystallized pose of $20 \alpha-\mathrm{OHP}$, with both naphthalene rings being located in the hydrophobic part of the AKR1C1 active site (Fig. 2). The most important predicted interaction is a hydrogen bond between one of the inhibitor carboxylates and Tyr55 of the catalytic tetrade. Also, the 
inhibitor NSC92412 forms mainly hydrophobic interactions: the indene ring is docked into the hydrophobic pocket that is formed by Ile129, Pro226, Val228, Leu306, Leu308 and Ile310. It is interesting to note that eHiTS did not predict the binding of the inhibitor hydroxyl group to the oxyanion hole, which is located at the bottom of the steroid-binding pocket and is formed by the catalytic tetrade residues Tyr55, His117, Asp50 and Lys84, and the cofactor nicotinamide ring. Instead, eHiTS predicted that the pyridine ring of inhibitor NSC92412 has $\pi$ stacking interactions with the nicotinamide ring of the cofactor $\mathrm{NADP}^{+}$, while the free hydroxyl group is pointing away from the catalytic tetrade.

While we were preparing this manuscript, Dhagat and co-workers published another virtual screening for the identification of new AKR1C1 inhibitors (Dhagat et al., 2007). They used a different approach, where the complete NCI open database of 250,000 compounds was first filtered with different physical and chemical filters and then docked with the structurebased screening program DOCK. 3,5-Diiodosalicylic acid and some related carboxylic acids (including salicylic and acetyl salicylic acid) were described as potent inhibitors of AKR1C1. However, the hit inhibitors obtained in the Dhagat study differ from the active compounds found with our virtual screening of the NCI Diversity Set. This is not surprising since different docking and scoring programs were used in the virtual screens.

To conclude, we have carried out virtual screening of compounds from the NCI database in our search for novel inhibitors of AKR1C1, an essential enzyme that is involved in progesterone metabolism and an emerging target for anticancer drug discovery. Fifty of the best ranked compounds were evaluated in in-vitro assays, and three hits were obtained that inhibit the enzyme in a low micromolar concentration range. These inhibitors represent promising starting points for further optimization. 


\section{Acknowledgements}

This work was supported the Ministry of Higher Education, Science and Technology of the Republic of Slovenia. The authors thank SimBioSys Inc. for a free academic license for eHiTS, Professor Trevor M. Penning for pcDNA3-AKR1C1 vector and Dr. Chris Berrie for critical reading of the manuscript. We would like to thank the Drug Synthesis and Chemistry Branch, Developmental Therapeutics Program, Division of Cancer Treatment and Diagnosis, National Cancer Institute for supplying the compounds for testing. 


\section{References}

Bauman, D.R., Rudnick, S., Szewczuk, L.M., Jin Y., Gopishetty, S., Penning, T.M., 2005 Development of non-steroidal anti-inflammatory drug (NSAID) analogs and steroid carboxylates selective for human aldo-keto reductase isoforms: Potential antineoplastic agents that work independently of cyclooxygenase isozymes. Mol. Pharmacol. 67, $60-68$.

Brožič, P., Šmuc, T., Gobec, S., Lanišnik Rižner T., 2006. Phytoestrogens as inhibitors of the human progesterone metabolizing enzyme AKR1C1. Mol. Cell. Endocrinol. 259, $30-42$.

Couture, J.F., Cantin, L., Legrand, P., Luu-The, V., Labrie, F., Breton, R., 2002. Expression, crystallization and preliminary X-ray analysis of human and rabbit $20 \alpha$-hydroxysteroid dehydrogenases in complex with $\mathrm{NADP}(\mathrm{H})$ and various steroid substrates. Acta. Cryst. D. $58,135-139$.

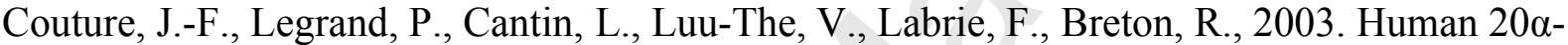
hydroxysteroid dehydrogenase: Crystallographic and site-directed mutagenesis studies lead to the identification of an alternative binding site for C21-steroids. J. Mol. Biol. $331,593-604$.

Dhagat, U., Carbone, V., Chung, R.P.-T., Matsunaga, T., Endo, S., Hara, A., El-Kabbani, O., 2007. A salicylic acid-based analogue discovered from virtual screening as a potent inhibitor of human 20 $\alpha$-hydroxysteroid dehydrogenase. Med. Chem. 3, 546-550.

Dufort, I., Labrie, F., Luu V., 2001. Human types 1 and 3 3a-hydroxysteroid dehydrogenases: Differential lability and tissue distribution. J. Clin. Endocrinol. Metab. 86, 841-846.

Dufort, I., Rheault, P., Huang, X.F., Soucy, P., Luu V., 1999. Characteristics of a highly labile human type 5 17beta-hydroxysteroid dehydrogenase. Endocrinology 140, 568-574.

Griffin, L.D., Mellon, S.H., 1999. Selective serotonin reuptake inhibitors directly alter activity of neurosteroidogenic enzymes. Proc. Natl. Acad. Sci. USA 96, 13512-13517.

Guido, R.V.C., Oliva, G., Andricopul, A. D., 2008. Virtual screening and its integration with modern drug design technologies. Curr. Med. Chem. 15, 37-46.

Higaki, Y., Usami, N., Shintani, S., Ishikura, S., El-Kabbani, O., Hara, O., 2003. Selective and potent inhibitors of human $20 \alpha$-hydroxysteroid dehydrogenase (AKR1C1) that metabolizes neurosteroids derived from progesterone. Chem. Biol. Interact. 143-144, 503-514.

Jornvall, H., Persson, B., Krook, M., Atrian, S., Gonzales-Duarte, R., Jefferey, J., Ghosh, D., 
1995. Short-chain dehydrogenase/reductases (SDRs). Biochemistry 34, 6003-6013.

Lanišnik Rižner, T., Šmuc, T., Rupreht, R., Šinkovec, J., Penning, T.M. 2006. AKR1C1 and AKR1C3 may determine progesterone and estrogen ratios in endometrial cancer. Mol. Cell. Endocrinol. 248, 126-135.

Nobel, S., Abrahamsen, L., Oppermann, U., 2001. Metabolic conversion as a pre-receptor control mechanism for lipophilic hormones. Eur. J. Biochem. 268, 4113-4125.

Penning, T.M., Burczynski, M.E., Jez, J.M., Lin, H.K., Ma, H., Moore, M., Palackal, N., Ratnam, K., 2000. Human 3alpha-hydroxysteroid dehydrogenase isoforms (AKR1C11C4) of the aldo-keto reductase superfamily: functional plasticity and tissue distribution reveals roles in the inactivation and formation of sex hormones. Biochem J. 351, 67-77.

Penning, T.M., 2003. Hydroxysteroid dehydrogenases and pre-receptor regulation of steroid hormone action. Hum. Reprod. Update 9, 193-205.

Persson, B., Krook, M., Jornvall, H., 1991. Characteristics of short-chain alcohol dehydrogenases and related enzymes. Eur. J. Biochem. 200, 537-543.

Usami, N., Yamamoto, T., Shintani, S., Higaki, Y., Ishikura, S., Katagiri, Y., Hara, A., 2002. Substrate specificity of human 3(20)alpha-hydroxysteroid dehydrogenase for neurosteroids and its inhibition by benzodiazepines. Biol. Pharm. Bull. 25, 441-445.

Zsoldos, Z., Reid, D., Simon, A., Sadjad, B., Johnson, A. P., 2006. A new fast, exhaustive flexible ligand docking system. J. Mol. Graph. Model. 7, 198-212.

Zsoldos, Z., Simon, A., Reid, D., Sadjad, B., Johnson, A.P., 2006. eHiTS: An innovative approach to the docking and scoring function problems. Curr. Prot. Pept. Sci. 7, 421435. 


\section{Figure Legends}

Figure 1. Reactions catalyzed by AKR1C1 in vivo.

Figure 2. Superimposition of the computer model of compound NSC292213 (light blue) on the X-ray structure of $20 \alpha$-hydroxyprogesterone (magenta) and $\mathrm{NADP}^{+}$(yellow) bound to AKR1C1. The residues of the catalytic tetrade (Asp50, Tyr55, Lys84 and His117) are depicted as blue sticks. All hydrophobic residues are shown as a semi-transparent yellow surface.

Figure 3. Superimposition of the computer model of compound NSC92412 (light blue) on the X-ray structure of $20 \alpha$-hydroxyprogesterone (magenta) and $\operatorname{NADP}^{+}$(yellow) bound to AKR1C1. The residues of the catalytic tetrade (Asp50, Tyr55, Lys84 and His117) are depicted as blue sticks. All hydrophobic residues are shown as a semi-transparent yellow surface. 
Table 1. The complete list of compounds evaluated biochemicaly after the virtual screening.

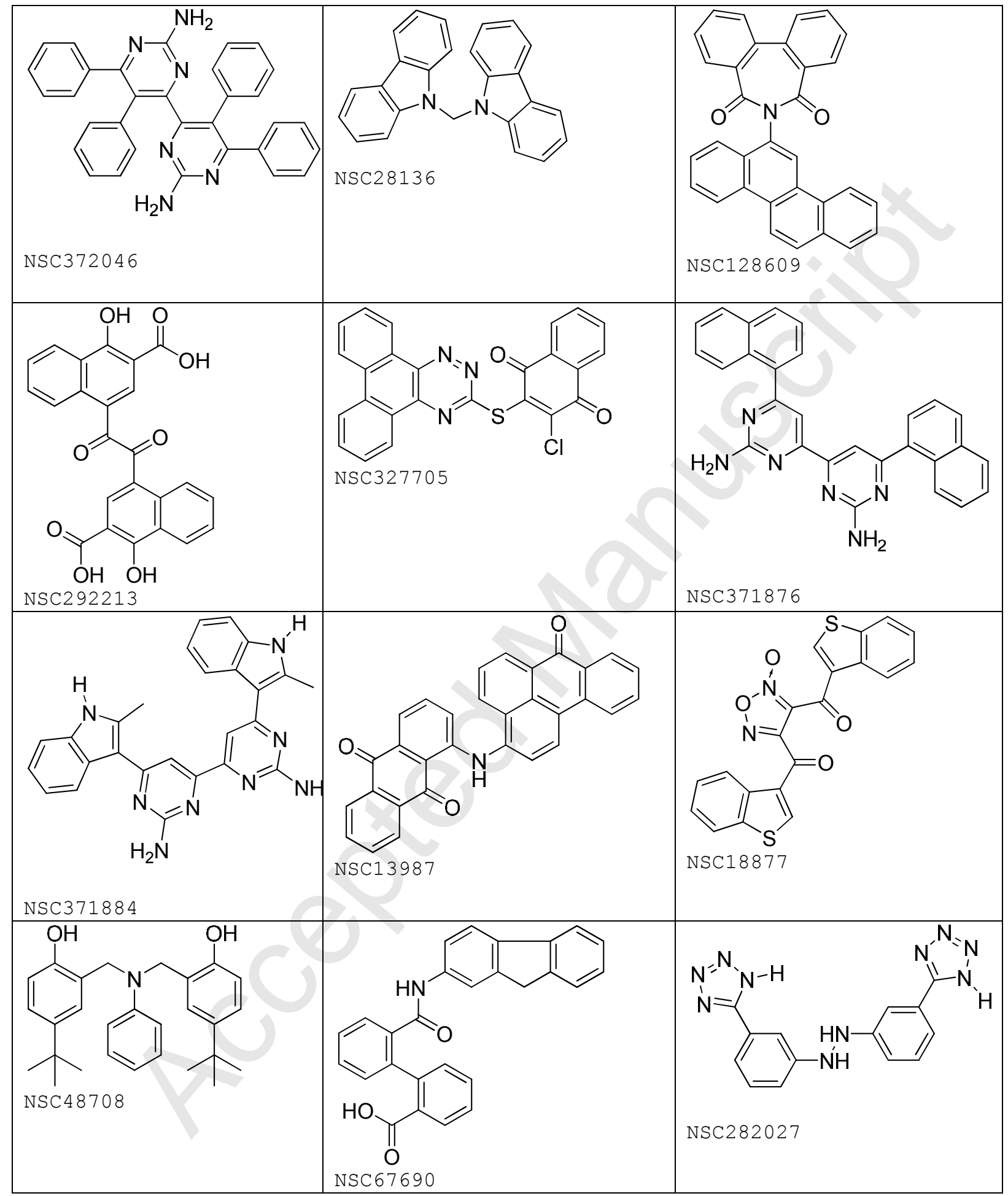




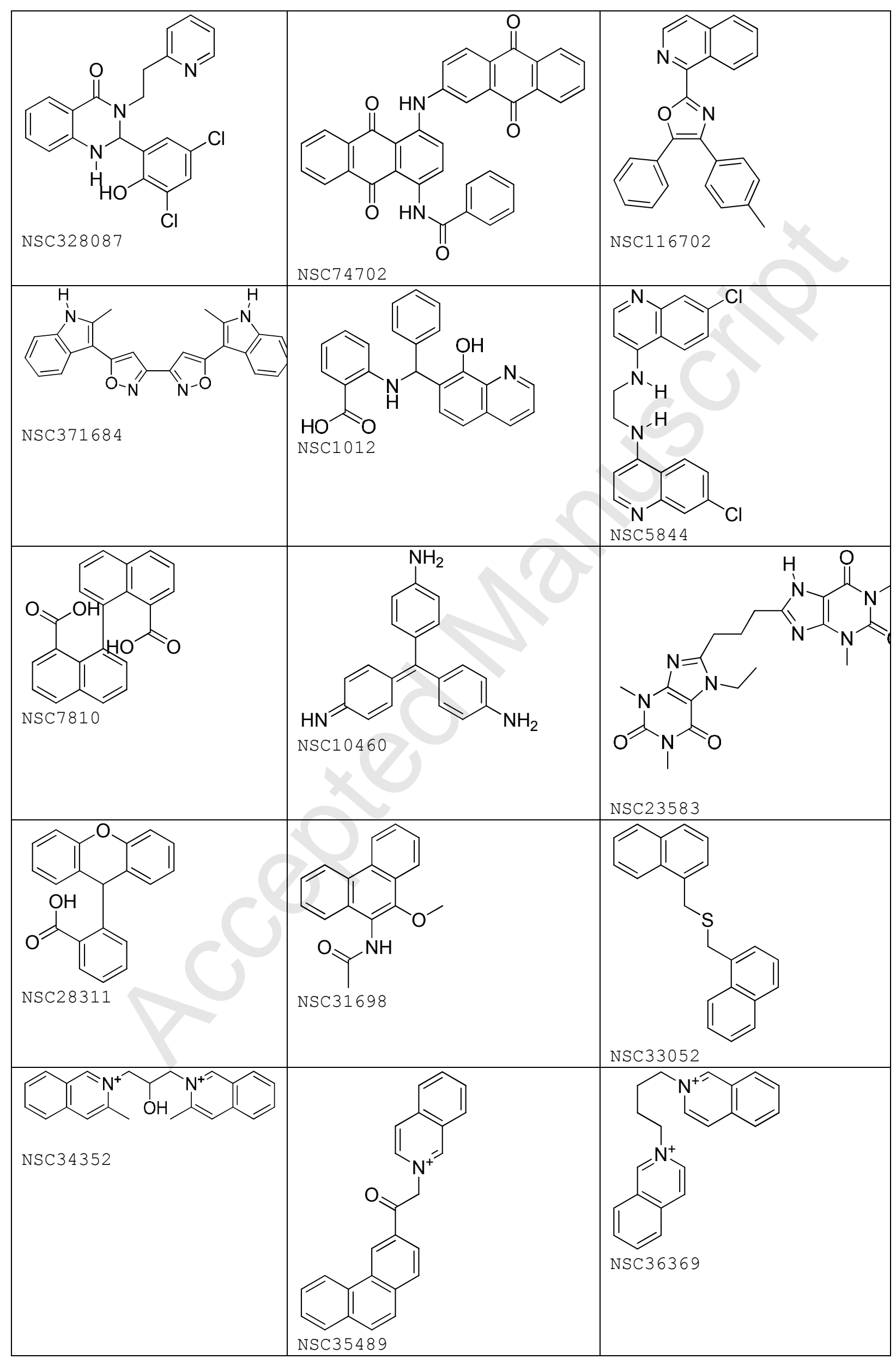




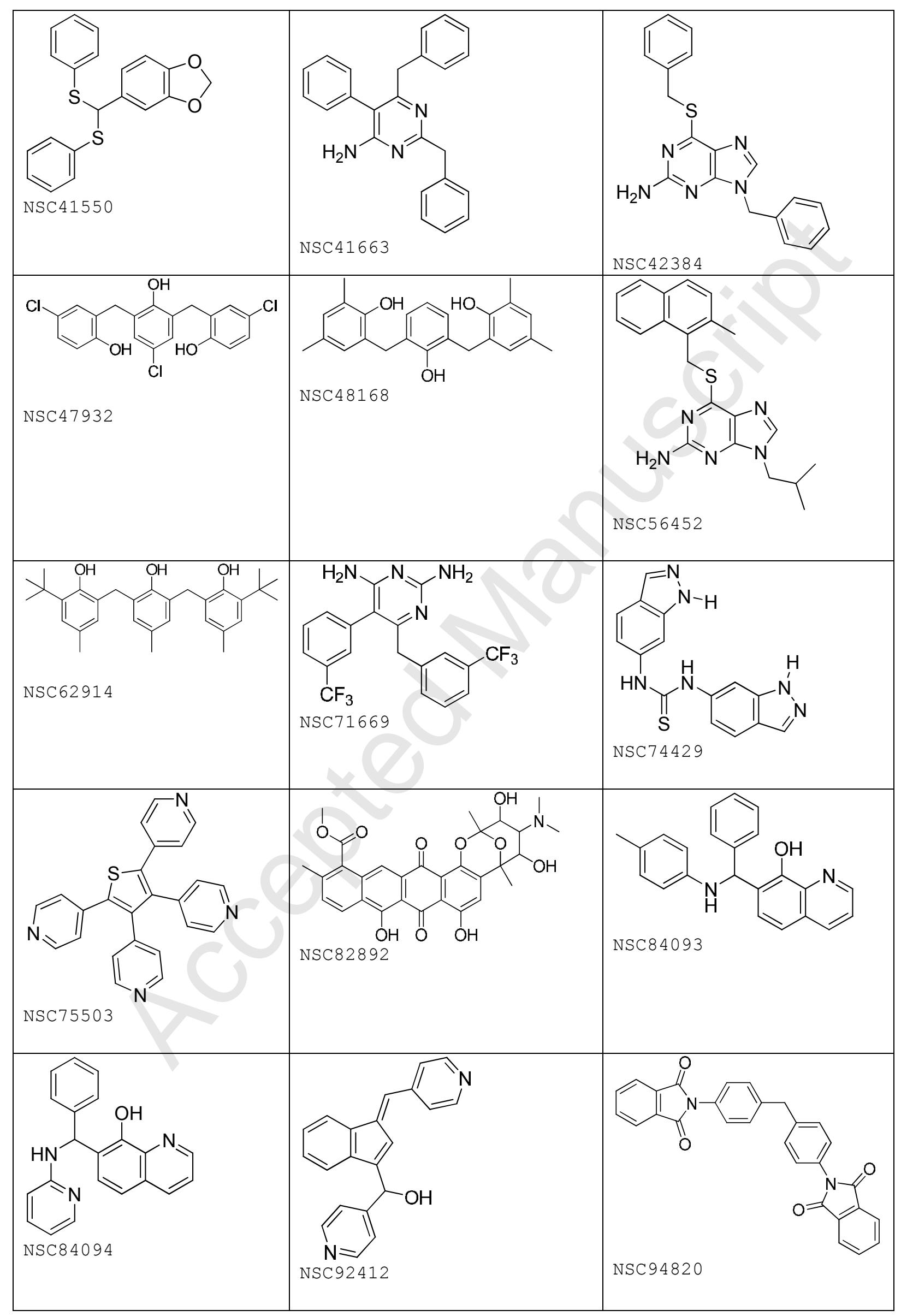




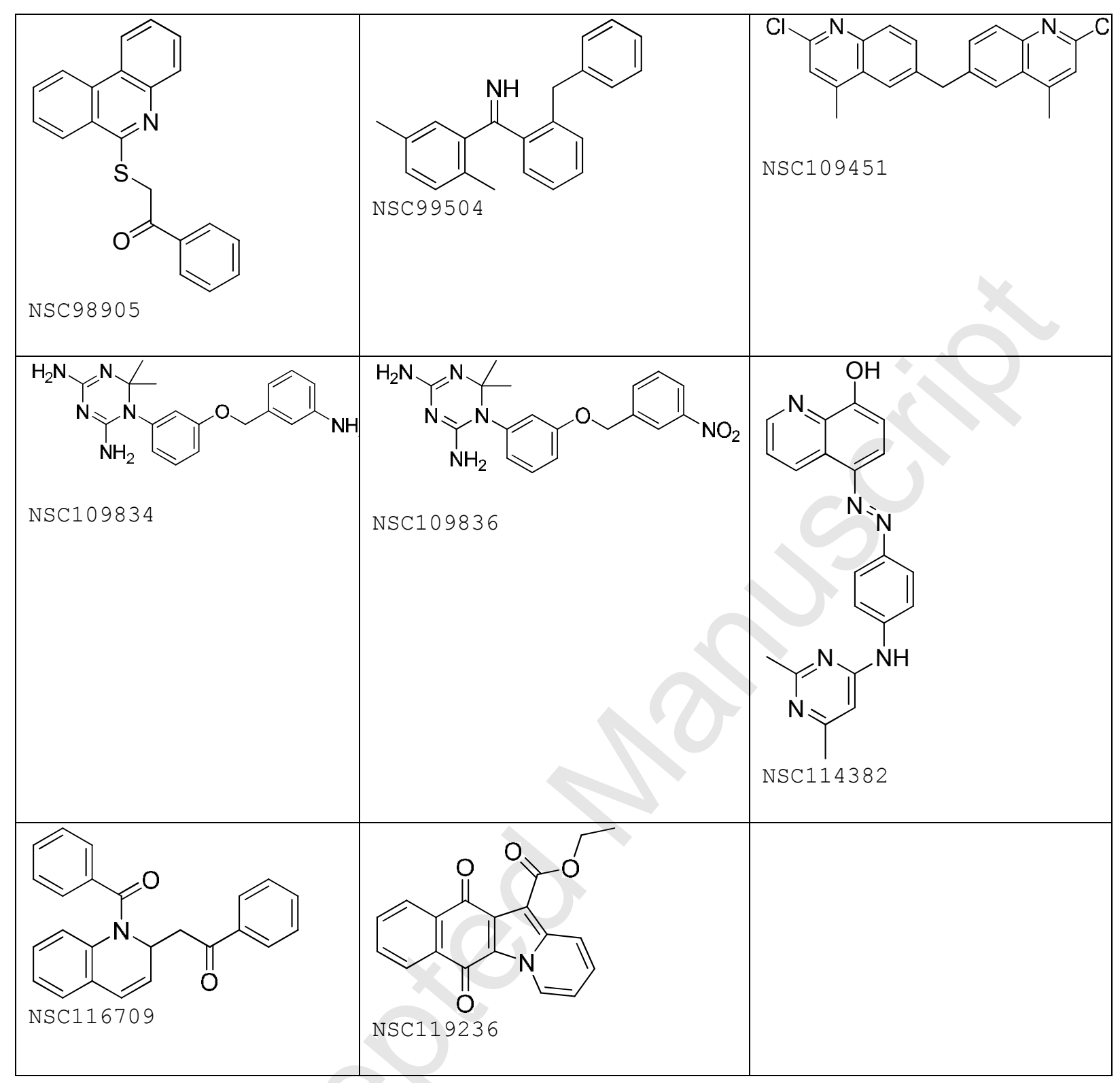


Table 2. The best inhibitors of AKR1C1 obtained after virtual screening and in-vitro evaluation.

\begin{tabular}{|c|c|c|c|}
\hline Compound & Rank by eHiTS & $\mathrm{IC}_{50}$ & Structure \\
\hline NSC292213 & 4 & $9.6 \mu \mathrm{M}$ & \\
\hline NSC327705 & 5 & $25.0 \mu \mathrm{M}$ & \\
\hline NSC92412 & 41 & $19.6 \mu \mathrm{M}$ & \\
\hline
\end{tabular}




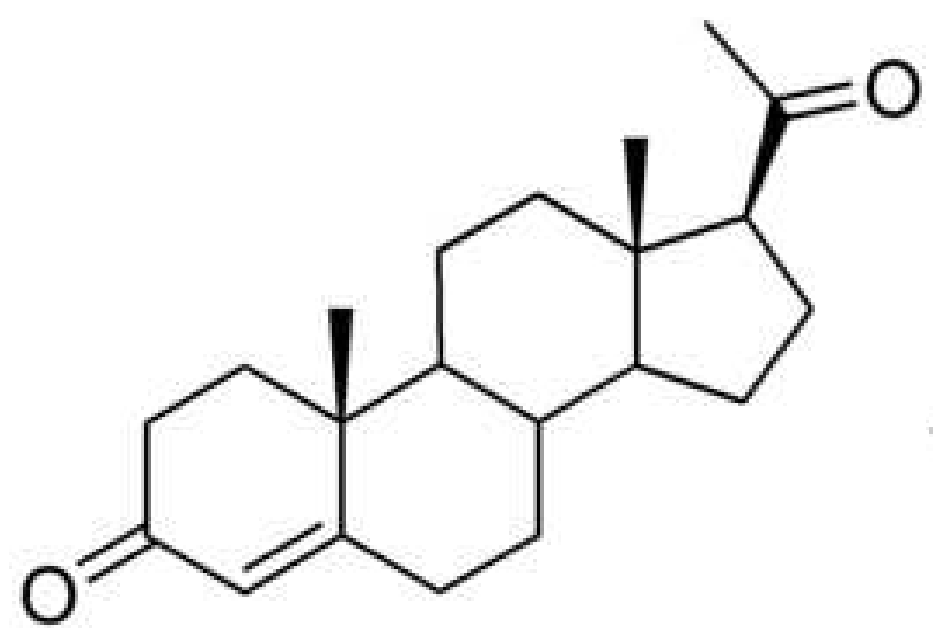

Progesterone $\stackrel{\text { AKR1C1 }}{\longrightarrow}$

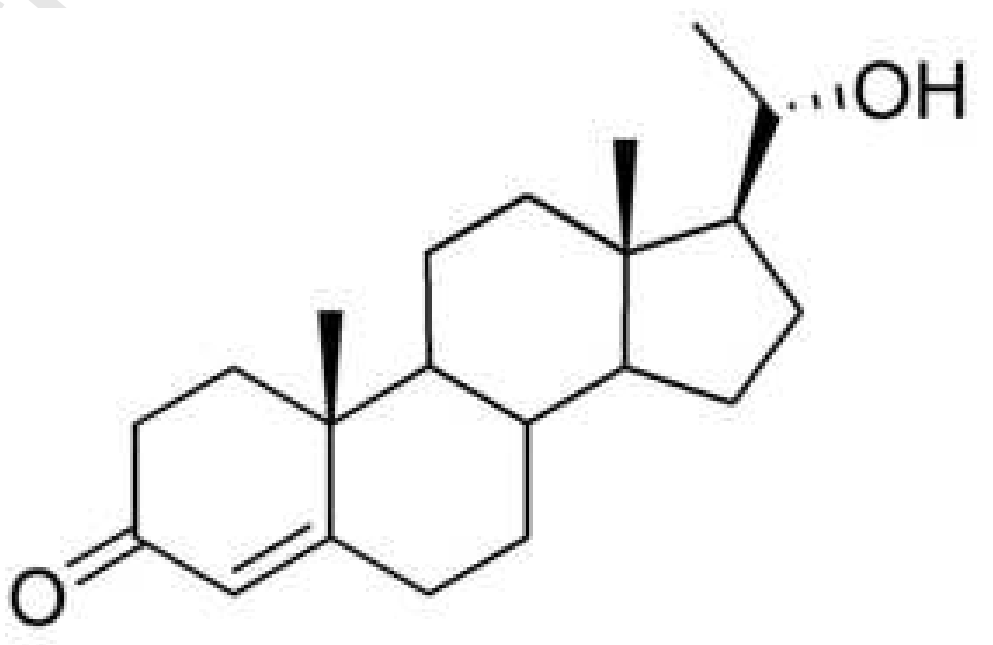

$20 \alpha$-Hydroxyprogesterone

$\stackrel{\text { AKR1C1 }}{\longrightarrow}$

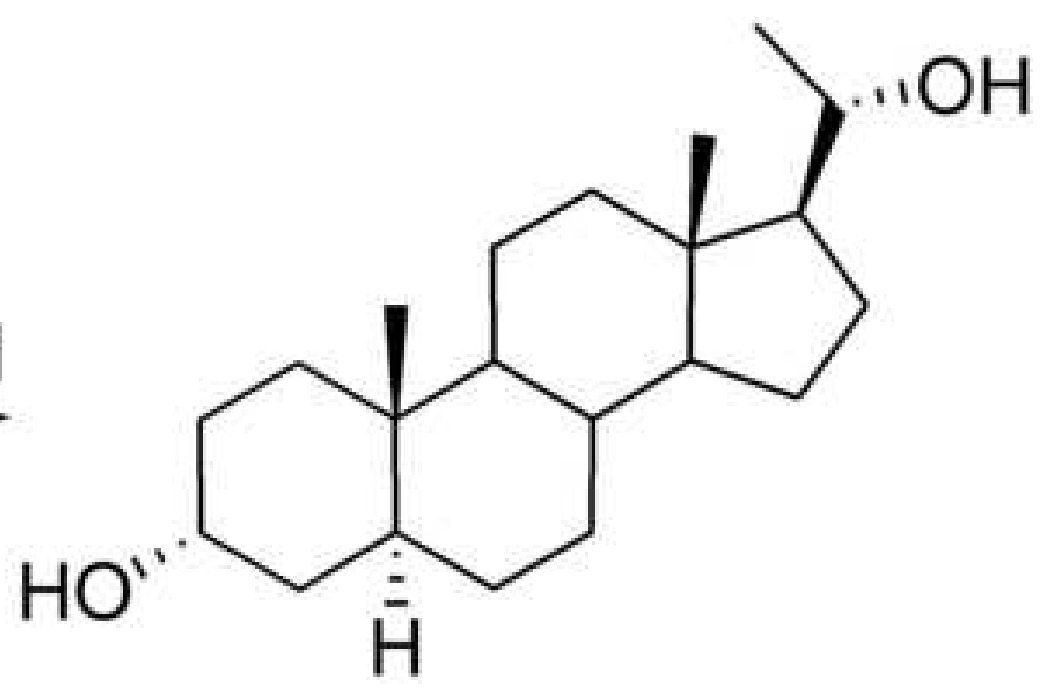

$3 \alpha, 5 \alpha$-Tetrahydroprogesterone

$5 \alpha$-Pregnane- $3 \alpha, 20 \alpha$-diol 


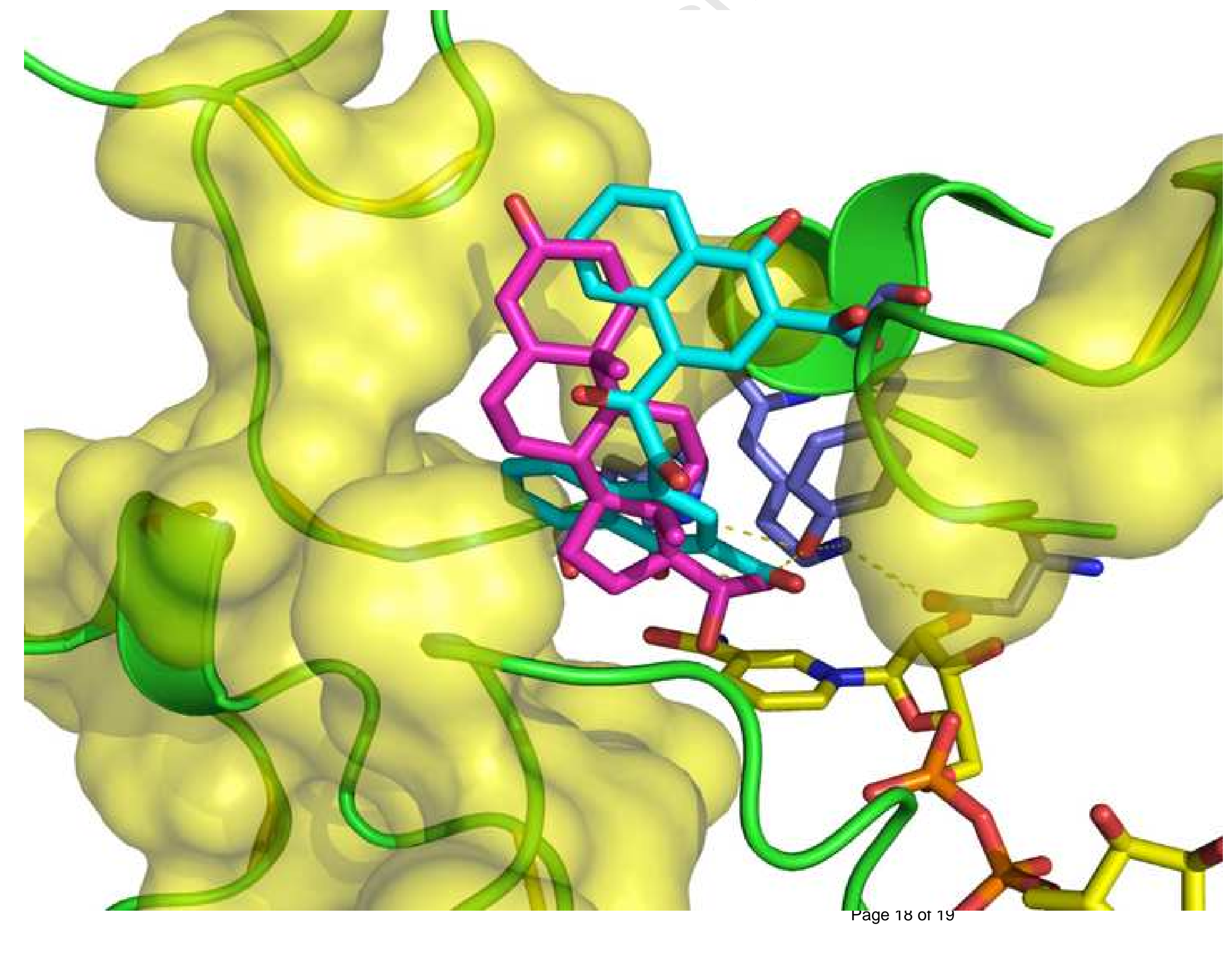

2
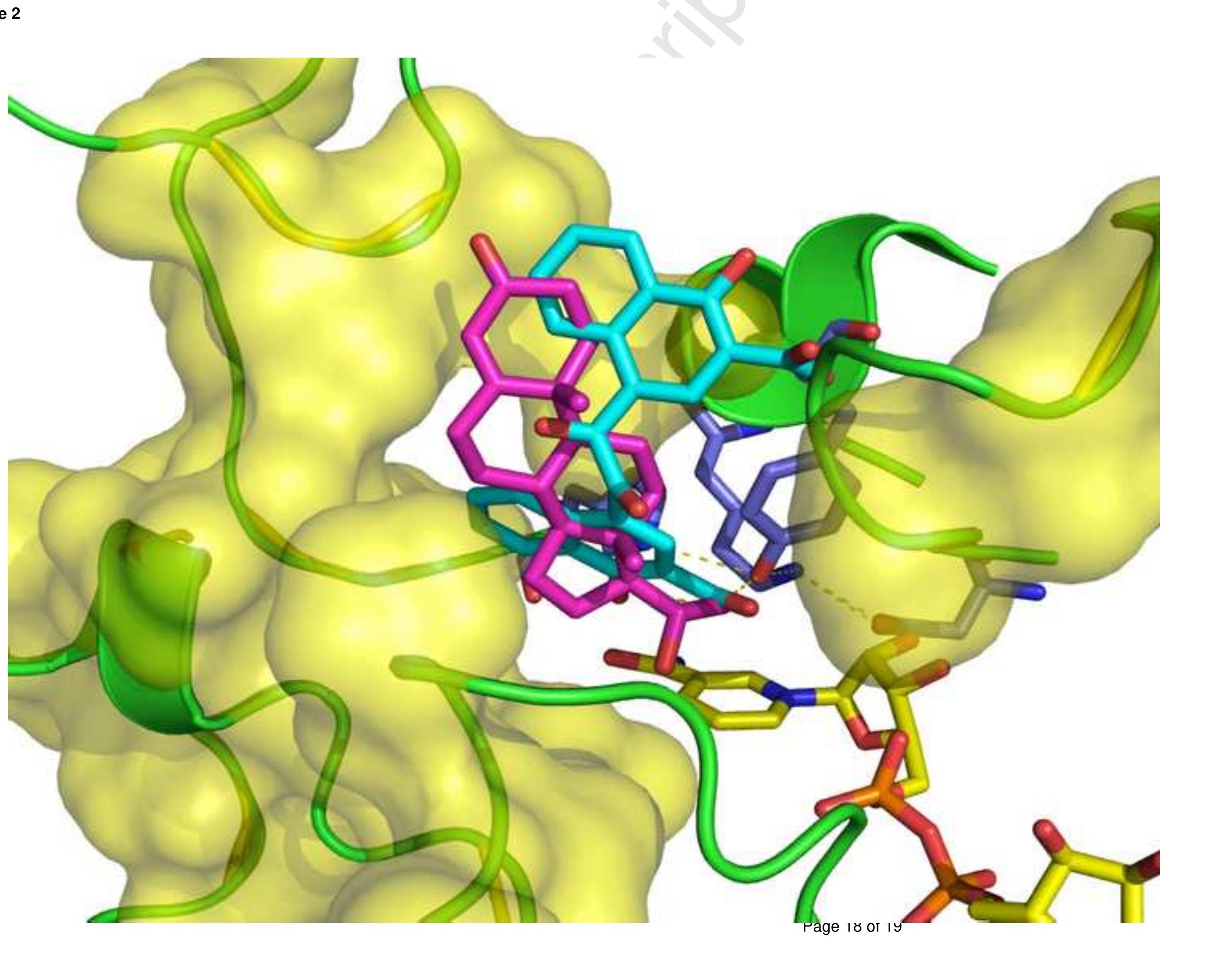


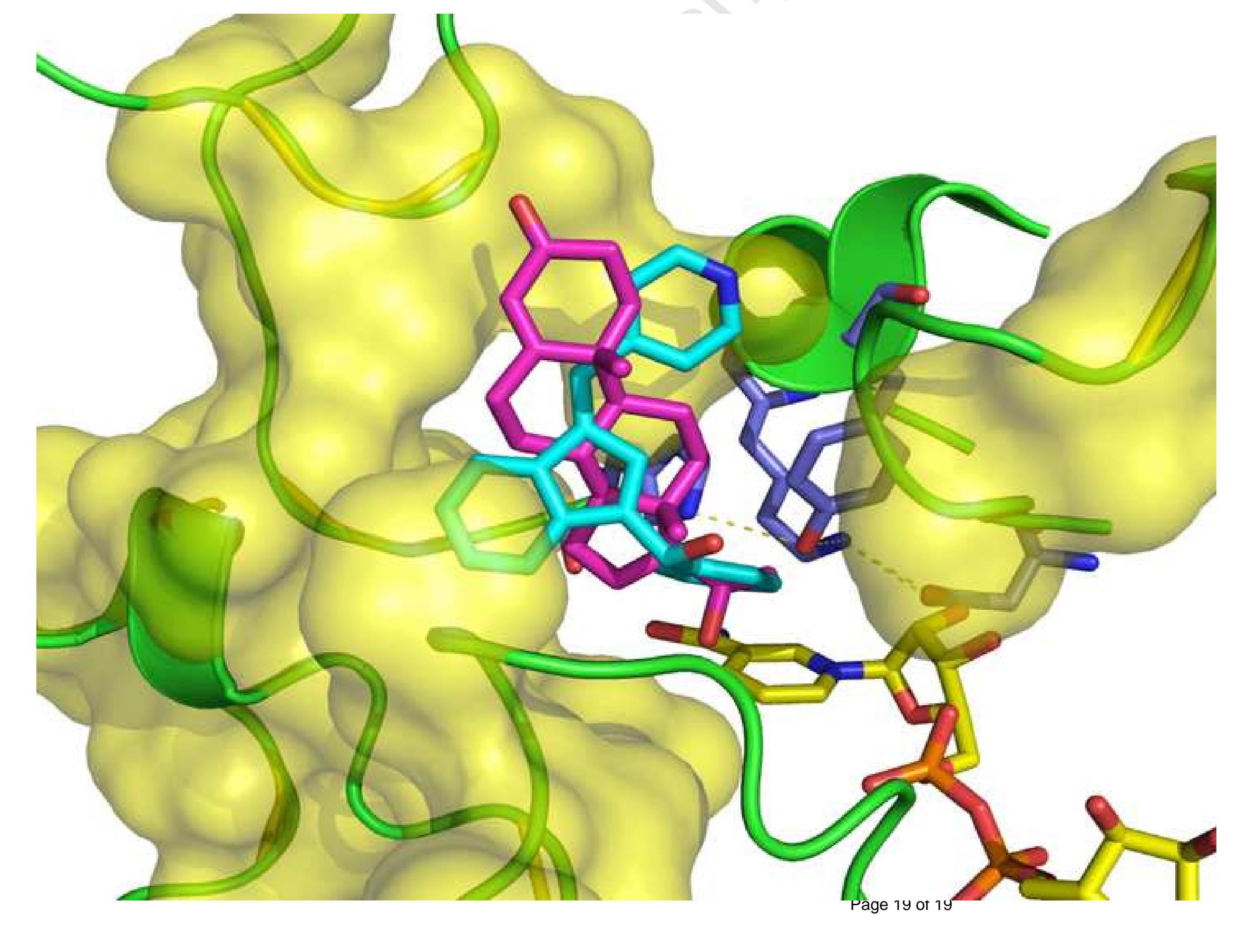

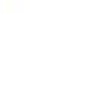

